\title{
Long-Term Cost-Effectiveness Analysis of Etanercept and Adalimumab for Plaque Psoriasis not Associated with Arthritis
}

\author{
Juan Ruano $\cdot$ Beatriz Isla-Tejera $\cdot$ Rafael Jiménez-Puya $\cdot$ \\ Ana Rodriguez-Martin • Manuel Cárdenas • Francisco Gómez • \\ A. Antonio Vélez · José R. del Prado-Llergo · José C. Moreno-Giménez
}

To view enhanced content go to www.dermtherapy-open.com

Received: May 17, 2013 / Published online: July 6, 2013

(c) The Author(s) 2013. This article is published with open access at Springerlink.com

\section{ABSTRACT}

Introduction: Pharmacoeconomic studies examining the cost-effectiveness of biological agents to treat moderate-to-severe psoriasis in real-life clinical practice are scarce. The aim of this study was to assess the efficiency, in terms of incremental cost-effectiveness, of etanercept and adalimumab in a real clinical setting.

J. Ruano and B. Isla-Tejera contributed equally to this work.

Electronic supplementary material The online version of this article (doi:10.1007/s13555-013-0030-1) contains supplementary material, which is available to authorized users.

J. Ruano $(\varangle) \cdot$ R. Jiménez-Puya ·

A. Rodriguez-Martin · F. Gómez · A. A. Vélez .

J. C. Moreno-Giménez

Department of Dermatology, Reina Sofía

University Hospital, Avda Menéndez Pidal s/n,

14004 Córdoba, Spain

e-mail: juanruanoruiz@mac.com

B. Isla-Tejera · M. Cárdenas · J. R. del Prado-Llergo Department of Pharmacy, Reina Sofía University Hospital, Córdoba, Spain

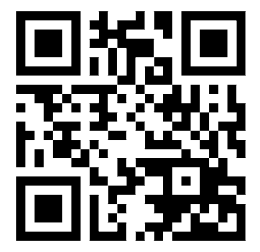

Enhanced content for this article is available on the journal web site: www.dermtherapy-open.com
Methods: Direct and indirect costs were assessed from a Spanish societal perspective in a historical hospital cohort of patients with moderate-tosevere psoriasis attending a tertiary referral hospital over a 1-year period. The data examined included drug-related variables, use of health-care resources, transportation and work productivity losses. Effectiveness was measured as the proportion of patients achieving a reduction of at least $75 \%$ with respect to the baseline value for the Psoriasis Area Severity Index (PASI 75) during the first 52 weeks of treatment.

Results: No statistically significant differences in effectiveness between etanercept $(n=135)$ and adalimumab $(n=48)$ were found (PASI 75 $80 \% \quad$ vs. $\quad 85.7 \% ; \quad \mathrm{RR}=1.07 \quad[0.90, \quad 1.27]$; $\mathrm{RRA}=5.7[-8.9,20.2] ; p=0.943)$. There were no significant differences in total cost per patient with etanercept as compared to adalimumab $\quad(14,843.73 \pm 6,178.98 € \quad$ vs. $15,405.91 \pm 9,106.50 € ; p=0.768)$.

Conclusion: Under conditions of daily clinical practice in our hospital, total health-care costs associated with the treatment of moderate-tosevere psoriasis with etanercept appear to be equivalent to those with adalimumab in the first year of treatment. 
Keywords: Adalimumab;

Moderate-to-severe

Pharmacoeconomic analysis

\section{INTRODUCTION}

Psoriasis is a highly morbid inflammatory disease of variable duration, extent and severity that involves skin and/or joints and which may affect patients' quality of life [1]. Biological drugs such as etanercept and adalimumab have considerably changed the therapeutic approach to this disease and enabled clinical control of a high proportion of patients [2, 3]. However, the substantial economic impact of these therapies on the national health system budget is a potential hindrance to their widespread use. The few costeffectiveness studies of biological therapies for psoriasis conducted to date have relied largely on clinical trials and have led to similar safety and efficiency results. Most of these studies involved incremental cost-effectiveness analyses of efficacy data obtained from clinical trials and adapted these to the social and economic peculiarities of the national health systems in the USA, Spain, Great Britain, Italy, Switzerland or Sweden, for example [4-10]. Thus, decision tree or hidden Markov models and Monte Carlo simulations were used to assess the cost-effectiveness of drugs such as infliximab [4-8, 10], etanercept [4-10], adalimumab [4-10], efalizumab [4, 6, 7], alefacept [8] and ustekinumab [7]. These studies measured effectiveness as the proportion of patients achieving a reduction of at least $75 \%$ with respect to the baseline value for the Psoriasis Area Severity Index (PASI 75) after 12 weeks $[4-8,10]$, and additionally, after 24 or 48 weeks in some studies $[6,9]$ with a few studies also linking the results to quality of life
$[5,9,10]$. However, all the studies that assessed the sensitivity of their incremental costeffectiveness estimates revealed an overlap between the studied drugs $[4-7,11]$. This is interesting as it reveals that effectiveness predictions from simulated data lead to similar results for different biological agents.

However, when trying to extrapolate such results into clinical practice, several factors need to be taken into consideration. For instance, clinical trials do not compare therapeutic choices, but rather individual drugs against a placebo. Also, most clinical trials comprise too short time periods to be representative of a disease, such as psoriasis, which has a chronic course that requires long-term treatment and where events occur that are usually not considered in these studies (e.g. suspension of the treatment after a period of sustained efficacy, dose elevations in response to recurrence, or withdrawal due to a lack or loss of efficacy or an adverse reaction). Moreover, the drugs used in clinical trials are administered in strict accordance with the recommendations in their technical sheets, but in clinical practice, there is evidence that physicians tend to manage patients using non-standard dosing patterns, intermediate doses, varying treatment interruption periods and increasing doses based on their own clinical judgement to achieve the therapeutic goal [12]. Based on this, we considered that observational studies providing a more accurate view of the use of biological drugs in clinical practice were required to test the hypothesis that etanercept and adalimumab exhibited no statistically significant differences in long-term costeffectiveness for the treatment of moderate-tosevere psoriasis in patients naïve to biological treatments [13]. This led us to assess the incremental cost-effectiveness of these drugs as first-choice biological treatments for moderate- 
to-severe plaque-type psoriasis using clinical practice data recorded at a reference hospital.

\section{MATERIALS AND METHODS}

\section{Population and Design}

\section{Design}

This was a retrospective, observational, singlecentre, pharmacoeconomic study designed to compare the cost-effectiveness of etanercept and adalimumab as first-choice biological therapies in a historical cohort of patients with moderate-tosevere psoriasis. Demographic and clinical information was obtained from patients' clinical histories, accessed via the report manager of the Reina Sofía University Hospital.

\section{Selection Criteria}

Selected patients were caucasian subjects of both sexes, aged 18-75 years and diagnosed with moderate-to-severe plaque-type psoriasis (PASI $>10 \%$, Dermatology Life Quality Index $>10$ and/or body surface area $>10 \%$ ) at least 1 year prior to the commencement of data collection; patients starting etanercept or adalimumab as first biological therapy over the period 2005-2010 and remaining on etanercept for at least 12 weeks and on adalimumab for 16 weeks. Exclusion criteria included the presence of other psoriasis varieties (guttata, inverse, ungueal, pustular, erythrodermic) or psoriatic arthritis diagnosed by a rheumatology specialist before or during the study period.

\section{Data Sources}

Treatment effectiveness and regime information was obtained from the patients' digital clinical histories. The cost considered for each drug was the laboratory sale price stated in the Spanish
Catalogue of Pharmaceutical Specialities plus value-added tax [14]. Unit costs per specialist visit, stay costs for the different medical services and day hospital admission costs were obtained from the Reina Sofia University Hospital's economic management database. Diagnostic test costs were obtained from Boletín Oficial de la Junta de Andalucía (BOJA), no. 217, dated 27 October 2005, which was in use by the Hospital Economic Unit at the time of the study to estimate such costs [15]. Work loss times and costs were calculated from the average annual gross salary published by Eurostat to estimate the average salary per worked hour on the assumption of a 40-h working week [16]. Productivity loss costs were calculated in terms of the time spent in transportation and health care in the hospital; an average time of $3.5 \mathrm{~h}$ per patient per visit was used for both outpatient visits and day hospital stays. Direct non-health costs incurred in relation to transportation from patients' homes to and from the hospital for each visit were estimated from the average between a taxi fare (lowest minimum fare plus a 1-km ride) and the urban bus fare when the transfer took place in the city, and the average cost of a 1-km ride in a medium-range car when the patient came from a different location [17-19].

The time spent undergoing supplementary tests was not considered since many were performed at health centres near the patients' homes. Also not considered were the time and costs associated with the administration of the drugs, since these were assumed to be essentially identical for both etanercept and adalimumab.

\section{Effectiveness}

Treatment effectiveness was measured as PASI 75, the main parameter of choice for assessing 
effectiveness in most clinical trials. Both absolute and incremental effectiveness were determined.

\section{Costs}

Cost analyses included direct costs (drug, healthcare resources, transportation) and indirect costs (productivity losses). Total associated costs were calculated by multiplying resource use by the corresponding unit cost. All costs are shown in euros $(€)$ and updated to July 2012.

\section{Economic Evaluation Method}

The time frame of the analysis was 1 year. The study was conducted from a Spanish social perspective, which was judged to be the most complete format, as it considered both direct and indirect costs and included a social impact. In this respect, the study departed from the usual, funder's approach.

\section{Regimes and Monitoring}

Incremental cost-effectiveness during the first 52 weeks of treatment was examined. Etanercept for adult treatment is available in subcutaneously administered 25 and $50 \mathrm{mg}$ doses. The recommended dose is usually $25 \mathrm{mg}$ twice a week or $50 \mathrm{mg}$ once a week or, optionally, $50 \mathrm{mg}$ twice a week [20]. The recommended dose for adalimumab is $40 \mathrm{mg}$ administered subcutaneously every second week, starting 1 week after the initial dose [21]. The dose, dosing interval and duration of the treatment regimen for each drug until its indefinite suspension were recorded. Costs associated with adverse reactions were excluded.

\section{Statistical Analysis}

The statistical methods used to describe centrality and dispersion of the data were the relative frequency (absolute frequency), followed by the minimum and maximum value for categorical variables and the arithmetic mean \pm standard deviation for quantitative variables. Statistically significant differences between the two treatments were established with the Chi-squared test for categorical variables and the Kruskall-Wallis test for quantitative variables. All computations were performed using different packages of the ' $\mathrm{R}$ ' statistical software system [22].

\section{RESULTS}

\section{Demographics and Patient Characteristics}

We examined the clinical histories of 1,998 patients with plaque-type psoriasis who visited the Dermatology Service of the Reina Sofía University Hospital over the period 2005-2010. A total of 183 patients starting etanercept $(n=135)$ or adalimumab $(n=48)$ as first-choice biological treatment during this period and complying with the inclusion criteria were selected for the study. The demographics and clinical characteristics of the patients are summarized in Table 1 . There were no statistically significant differences between the two drug groups in most of the parameters. The only differences observed were in the frequencies of allergic rhinitis and asthmatic bronchitis (both $P<0.001$, respectively). All other characteristics were similar in both treatment groups; therefore we deemed these differences to be irrelevant when interpreting the results. During the first year, there were 14 dropouts (3: lack of adherence; 7: loss of efficacy; 4 adverse events). Only in four patients ( 3 in the etanercept group and 1 in the adalimumab group) was the drug withdrawn due to adverse reactions, but the adverse events 
Table 1 Baseline characteristics of the patients in each treatment group

\begin{tabular}{|c|c|c|c|}
\hline & $\begin{array}{l}\text { Etanercept } \\
(n=135)\end{array}$ & $\begin{array}{l}\text { Adalimumab } \\
(n=48)\end{array}$ & $P$ value* \\
\hline \multicolumn{4}{|l|}{ Demographic characteristics } \\
\hline Age (years) & $45(19-78)$ & $42(18-73)$ & n.s. \\
\hline Gender (male/female) & $99 / 52$ & $35 / 13$ & n.s. \\
\hline Body weight $(\mathrm{kg})$ & $79 \pm 17$ & $82 \pm 16$ & n.s. \\
\hline Height $(\mathrm{cm})$ & $168 \pm 8$ & $170 \pm 11$ & n.s. \\
\hline BMI $\left(\mathrm{kg} / \mathrm{m}^{2}\right)$ & $28.1 \pm 4.5$ & $29.2 \pm 9$ & n.s. \\
\hline $\begin{array}{l}\text { Duration of psoriasis } \\
\text { (years) }\end{array}$ & $13.7(1-59)$ & $15.4(1-34)$ & n.s. \\
\hline \multicolumn{4}{|l|}{ Concomitant treatment } \\
\hline Methotrexate & $1(0.6 \%)$ & $2(4.1 \%)$ & n.s. \\
\hline Acitretin & $0(0 \%)$ & $1(2 \%)$ & n.s. \\
\hline Ciclosporin & $0(0 \%)$ & $0(0 \%)$ & n.s. \\
\hline Phototherapy & $0(0 \%)$ & $2(4.1 \%)$ & n.s. \\
\hline \multicolumn{4}{|l|}{ Comorbidity } \\
\hline $\begin{array}{l}\text { Smoker/ex-smoker/ } \\
\text { non-smoker }\end{array}$ & $8 / 4 / 124$ & $6 / 2 / 40$ & n.s. \\
\hline Hypertension & $22(16.2 \%)$ & $10(21 \%)$ & n.s. \\
\hline Diabetes & $13(9.6 \%)$ & $6(12.5 \%)$ & n.s. \\
\hline Obesity & $43(32 \%)$ & $13(27 \%)$ & n.s. \\
\hline Hyperlipidaemia & $13(9.6 \%)$ & $6(12.5 \%)$ & n.s. \\
\hline Cardiovascular disease & $7(5.1 \%)$ & $3(7.1 \%)$ & n.s. \\
\hline Chronic renal insufficiency & $1(0.7 \%)$ & $0(0 \%)$ & n.s. \\
\hline Epilepsy & $1(0.7 \%)$ & $0(0 \%)$ & n.s. \\
\hline $\begin{array}{l}\text { Hiatus hernia/ } \\
\text { gastroduodenal ulcer }\end{array}$ & $4(2.8 \%)$ & $0(0 \%)$ & n.s. \\
\hline $\begin{array}{l}\text { Liver steatosis/chronic liver } \\
\quad \text { disease }\end{array}$ & $3(2.2 \%)$ & $3(7.1 \%)$ & n.s. \\
\hline $\begin{array}{l}\text { Ulcerous colitis/Crohn's } \\
\text { disease }\end{array}$ & $0(0 \%)$ & $2(4.1 \%)$ & n.s. \\
\hline $\begin{array}{l}\text { Atrophic chronic ulcer/ } \\
\text { pernicious anaemia }\end{array}$ & $2(1.4 \%)$ & $0(0 \%)$ & n.s. \\
\hline $\begin{array}{l}\text { Anxiety/depression or } \\
\text { schizophrenia }\end{array}$ & $8(5.9 \%)$ & $2(4.1 \%)$ & n.s. \\
\hline $\begin{array}{l}\text { Allergic rhinitis/asthmatic } \\
\text { bronchitis }\end{array}$ & $11(8.1 \%)$ & $0(0 \%)$ & $<0.001$ \\
\hline $\begin{array}{l}\text { Apnoea syndrome/sleep } \\
\text { hypopnoea }\end{array}$ & $1(0.7 \%)$ & $2(4.1 \%)$ & n.s. \\
\hline $\begin{array}{l}\text { Chronic obstructive } \\
\text { pulmonary disease }\end{array}$ & $3(2.2 \%)$ & $2(4.1 \%)$ & n.s. \\
\hline Gout/hyperuricaemia & $3(2.2 \%)$ & $0(0 \%)$ & n.s. \\
\hline Hypothyroidism & $5(3.7 \%)$ & $0(0 \%)$ & n.s. \\
\hline Glaucoma & $1(0.7 \%)$ & $0(0 \%)$ & n.s. \\
\hline Prostatic adenoma & $3(2.2 \%)$ & $0(0 \%)$ & n.s. \\
\hline Hodgkin's lymphoma & $1(0.7 \%)$ & $0(0 \%)$ & n.s. \\
\hline
\end{tabular}

Values are mean $\pm \mathrm{SD}$ or median (range)

$B M I$ body mass index

${ }^{*} \mathrm{Chi}^{2}$ with Yates correction for categorical variables and Kruskall-Wallis test for quantitative variables were described accurately in the clinical history of only one of these cases.

\section{Effectiveness}

There were no statistically significant differences in PASI 75 during the first 52 weeks of treatment between etanercept and adalimumab $[80.0 \%$ vs $85.7 \%$; relative risk $(\mathrm{RR})=1.07(0.90,1.27)$; relative risk aversion $($ RRA $)=5.7(-8.9,20.2) ; P=0.943]$. Therefore, both drugs were deemed similarly effective during the study period.

\section{Costs}

Supplementary Table 1 shows the unit costs of the drugs, health-care resources, transportation and work loss values used in the analysis. The total drug cost for the first year of treatment was $€ 1,893,180.75$ for etanercept and $€ 696,404.16$ for adalimumab. The cost per patient was thus $€ 14,451.76 \pm 5,606.17$ for etanercept and $€ 14,508.42 \pm 9,072.35$ for adalimumab. Table 2 shows that the costs of an internal medicine specialist outpatient and day hospital visits, simple X-rays and dermatology inpatient visits were lower for etanercept as compared to adalimumab (all $P<0.05$ ). Nevertheless, there were no significant differences in total healthcare resource costs between both treatment groups. When analysing work productivity losses (Table 3) and patients' transportation expenditure (Table 4), a significant increase was found in the cost associated with visits to the internal medicine specialist in the group treated with adalimumab compared with etanercept (all $P<0.05$ ). However, these differences did not contribute to the total work productivity losses or patients' transportation costs, which resulted in no statistically different overall costs between 
Table 2 Analysis of costs associated with health-care resource use during the first year of treatment with etanercept and adalimumab

\begin{tabular}{|c|c|c|c|c|c|c|c|}
\hline \multirow[t]{2}{*}{ Resource } & \multicolumn{3}{|c|}{ Etanercept $(n=135)$} & \multicolumn{4}{|c|}{ Adalimumab $(n=48)$} \\
\hline & Units & $\begin{array}{l}\text { Total cost } \\
(€)\end{array}$ & $\begin{array}{l}\text { Mean cost per } \\
\text { patient }(€)\end{array}$ & Units & $\begin{array}{l}\text { Total cost } \\
(€)\end{array}$ & $\begin{array}{l}\text { Mean cost per } \\
\text { patient }(€)\end{array}$ & $\overline{P^{*} \text { value }}$ \\
\hline \multicolumn{8}{|l|}{ Outpatient service } \\
\hline \multicolumn{8}{|l|}{ Dermatology } \\
\hline First visit & 135 & $5,872.50$ & $43.50(0)$ & 48 & $2,088.00$ & $43.50(0.00)$ & n.a. \\
\hline Follow-up visit & 1,158 & $20,612.40$ & $157.89(55.30)$ & 406 & $7,442.60$ & $155.11(58.731)$ & n.s. \\
\hline Subtotal & 1,293 & $26,484.90$ & $194.92(63.61)$ & 454 & $9,530.60$ & $198.61(58.71)$ & n.s. \\
\hline \multicolumn{8}{|l|}{ Rheumatology } \\
\hline First visit & 16 & 696.00 & $5.12(14.07)$ & 10 & 298.08 & $6.21(15.50)$ & n.s. \\
\hline Follow-up visit & 23 & 409.40 & $3.01(10.29)$ & 20 & 518.88 & $10.81(32.26)$ & n.s. \\
\hline Subtotal & 39 & $1,105.40$ & $8.13(23.16)$ & 30 & 816.96 & $17.02(46.01)$ & n.s. \\
\hline \multicolumn{8}{|l|}{ Digestive system } \\
\hline First visit & 8 & 348.00 & $2.56(10.27)$ & 6 & 298.08 & $6.21(15.50)$ & n.s. \\
\hline Follow-up visit & 20 & 356.00 & $2.62(12.36)$ & 13 & 244.32 & $5.09(19.29)$ & n.s. \\
\hline Subtotal & 28 & 704.00 & $5.18(21.78)$ & 19 & 542.40 & $11.30(31.71)$ & n.s. \\
\hline \multicolumn{8}{|l|}{ Internal medicine } \\
\hline First visit & 3 & 130.50 & $0.96(6.41)$ & 5 & 223.68 & $4.66(13.70)$ & 0.029 \\
\hline Follow-up visit & 4 & 71.20 & $0.52(4.30)$ & 10 & 182.88 & $3.81(14.82)$ & n.s. \\
\hline Subtotal & 7 & 201.70 & $1.48(10.22)$ & 15 & 406.56 & $8.47(26.73)$ & 0.028 \\
\hline \multicolumn{8}{|l|}{ Infectious disease } \\
\hline First visit & 3 & 130.50 & $0.96(6.41)$ & 0 & 0.00 & - & \\
\hline Follow-up visit & 4 & 71.20 & $0.52(4.30)$ & 0 & 0.00 & - & n.a. \\
\hline Subtotal & 7 & 201.70 & $1.48(10.22)$ & 0 & 0.00 & - & n.a. \\
\hline Emergency visits & 10 & 540.76 & $3.98(23.39)$ & 0 & 0.00 & - & n.a. \\
\hline \multicolumn{8}{|l|}{ Radiology } \\
\hline Simple X-ray & 143 & $1,319.89$ & $9.71(14.58)$ & 78 & 791.04 & $16.48(17.65)$ & 0.031 \\
\hline CAT & 5 & 523.05 & $3.85(23.51)$ & 0 & 0.00 & - & n.a. \\
\hline NMR & 3 & 682.41 & $5.02(33.53)$ & 1 & 227.47 & $8.12(42.99)$ & n.s. \\
\hline Ecography & 8 & 295.36 & $2.17(9.81)$ & 5 & 190.08 & $3.96(15.37)$ & n.s. \\
\hline Subtotal & 159 & $2,820.71$ & $20.74(51.20)$ & 84 & $1,208.59$ & $28.56(48.73)$ & 0.042 \\
\hline \multicolumn{8}{|l|}{ Day hospital } \\
\hline Dermatology & 8 & $1,284.00$ & $9.51(94.21)$ & 17 & $2,751.36$ & $57.32(303.32)$ & n.s. \\
\hline
\end{tabular}


Table 2 continued

\begin{tabular}{|c|c|c|c|c|c|c|c|}
\hline \multirow[t]{2}{*}{ Resource } & \multicolumn{3}{|c|}{ Etanercept $(n=135)$} & \multicolumn{4}{|c|}{ Adalimumab $(n=48)$} \\
\hline & Units & $\begin{array}{l}\text { Total cost } \\
(€)\end{array}$ & $\begin{array}{l}\text { Mean cost per } \\
\text { patient }(€)\end{array}$ & Units & $\begin{array}{l}\text { Total cost } \\
(€)\end{array}$ & $\begin{array}{l}\text { Mean cost per } \\
\text { patient }(€)\end{array}$ & $P^{*}$ value \\
\hline Rheumatology & 3 & 481.50 & $3.54(30.68)$ & 0 & 0.00 & - & n.a. \\
\hline Infectious diseases & 0 & - & - & 0 & 0.00 & - & n.a. \\
\hline Subtotal & 11 & $1,765.50$ & $12.98(97.78)$ & 17 & $2,751.00$ & $57.32(303.32)$ & n.s. \\
\hline \multicolumn{8}{|l|}{ Inpatient service } \\
\hline Dermatology & 0 & 0 & - & 27 & $18,042.72$ & $375.89(1,989.05)$ & 0.027 \\
\hline Internal medicine & 0 & 0 & - & 12 & $5,052.48$ & $105.26(557)$ & 0.027 \\
\hline Digestive system & 0 & 0 & - & 0 & 0.00 & - & n.a. \\
\hline Subtotal & 0 & 0 & - & 39 & $23,095.68$ & $481.16(2,546.04)$ & 0.027 \\
\hline Total health resource cost & 1,554 & $33,825.21$ & $248.90(148.3)$ & 658 & $37,144.40$ & $802.45(2,594.67)$ & n.s. \\
\hline
\end{tabular}

CAT Computer axial tomography, n.a. not applicable, NMR nuclear magnetic resonance, n.s. not significant

Reported within parentheses are standard deviation values

* Kruskall-Wallis test for the quantitative variable 'mean cost per patient' comparing both drugs

both drugs. Table 5 shows the total cost of each treatment choice. There were no significant differences in total cost per patient with etanercept compared with adalimumab.

\section{Cost-Effectiveness Analysis}

The absence of statistically significant differences in effectiveness between the two treatments excluded a cost-effectiveness analysis, which was replaced with a cost minimization analysis. This included not only drug costs, but also direct costs derived from the use of resources, patients' transportation and indirect (work productivity loss) costs.

\section{DISCUSSION}

This study approached cost-effectiveness analysis from a novel, broad perspective, in social terms and based on observational data. This strengthens the applicability of its results to similar populations, as it reduces uncertainty in the decision-making process in clinical practice when using estimates of pharmacoeconomic studies based on clinical trial data.

However, our approach is subject to several methodological limitations that warrant some comment. The single-centre, retrospective design used in this study may have detracted from the representative nature of the results owing to inaccuracies in the patients' clinical histories. This potential bias, which is inherent in most retrospective work, is a result of the lack of well-defined standards for recording visits and of variability in clinical practice-two distinct features of clinical trial designs. In any case, our results could be validated by a future standardized, multi-centre, prospective study.

One other potential shortcoming of our study was the exclusion of costs arising from the management of adverse reactions to etanercept and adalimumab. The exclusion of 
Table 3 Analysis of total and per-patient costs in relation to work productivity losses during the first year of treatment with etanercept and adalimumab

\begin{tabular}{|c|c|c|c|c|c|c|c|}
\hline & \multicolumn{3}{|c|}{ Etanercept $(n=135)$} & \multicolumn{4}{|c|}{ Adalimumab $(n=48)$} \\
\hline & Units & $\begin{array}{l}\text { Total cost } \\
(€)\end{array}$ & $\begin{array}{l}\text { Mean }(S D) \text { cost } \\
\text { per patient }(€)\end{array}$ & Units & $\begin{array}{l}\text { Total cost } \\
(€)\end{array}$ & $\begin{array}{l}\text { Mean }(S D) \text { cost } \\
\text { per patient }(€)\end{array}$ & $P^{*}$ value \\
\hline \multicolumn{8}{|l|}{ Outpatient service } \\
\hline Dermatology & 1,293 & $48,377.60$ & $369.25(116.23)$ & 454 & $17,443.68$ & 363.41 (123.39) & n.s. \\
\hline Rheumatology & 39 & $1,459.19$ & $10.73(32.17)$ & 31 & $1,539.36$ & $32.07(78.68)$ & n.s. \\
\hline Digestive system & 28 & $1,047.62$ & $7.70(33.81)$ & 20 & 769,44 & $16.03(50.32)$ & n.s. \\
\hline Internal medicine & 7 & 261.91 & $1.93(13.90)$ & 15 & 576,96 & $12.02(40.79)$ & 0.028 \\
\hline Infectious diseases & 7 & 261.91 & $1.93(13.90)$ & 0 & - & - & n.s. \\
\hline Subtotal & 1,374 & $51,408.21$ & $377.95(149.52)$ & 520 & $20,329.44$ & $423.53(189.68)$ & n.s. \\
\hline \multicolumn{8}{|l|}{ Day hospital } \\
\hline Dermatology & 8 & 299.32 & $2.20(16.27)$ & 17 & 641.28 & $13.36(21.70)$ & n.s. \\
\hline Rheumatology & 3 & 112.25 & $0.83(7.15)$ & 0 & - & - & n.a. \\
\hline Infectious diseases & 0 & 0.00 & - & 0 & - & - & n.a. \\
\hline Subtotal & 11 & 411.57 & $3.03(22.79)$ & 17 & 641.28 & $13.36(21.70)$ & n.s. \\
\hline Total productivity loss & 1,385 & $51,819.78$ & $380.98(150.76)$ & 537 & $20,970.72$ & $436.90(234.85)$ & n.s. \\
\hline
\end{tabular}

$S D$ standard deviation; n.a. not applicable, n.s. not significant

${ }^{*}$ Kruskall-Wallis test for the quantitative variable 'mean cost per patient' comparing both drugs

these costs was dictated by the poor documentation of such reactions in the clinical histories. Based on previous studies and a recent report issued by the United Kingdom's National Institute for Health and Clinical Excellence, there are no significant differences in adverse reactions between both drugs [23]; therefore, any such differences can be assumed to have led to no additional disparities in cost between the two treatment groups in our study.

Finally, the treatment groups in our study differed markedly in the number of patients, largely as a result of etanercept being made commercially available 1 year earlier than adalimumab. Thus, after the first year, adalimumab played a secondary role and was preserved for use in patients refractory to etanercept, even though no such application was stated in its technical sheet. Moreover, a large number of patients in the adalimumab group had psoriatic arthritis in addition to plaque psoriasis; therefore, these patients were excluded to avoid biased estimation of the costs associated with the use of health-care resources. Also, alternative biologicals currently in use to treat moderate-to-severe psoriasis in our hospital (e.g. infliximab and ustekinumab) were excluded, since they are administered intravenously and only at the hospital-a marked difference from etanercept and adalimumab. In addition, these alternative biological agents are prescribed mostly for patients with arthritis and/or those selected for rescue with other biologicals. In addition, the use frequency of ustekinumab as a first-choice 
Table 4 Analysis of total and per-patient costs associated with return transportation between patients' homes and the hospital during the first year of treatment with etanercept and adalimumab

\begin{tabular}{|c|c|c|c|c|c|c|c|c|c|}
\hline & \multicolumn{4}{|c|}{ Etanercept $(n=135)$} & \multicolumn{5}{|c|}{ Adalimumab $(n=48)$} \\
\hline & Trips & $\begin{array}{l}\text { Total } \\
\text { distance per } \\
\text { patient }(\mathbf{k m})\end{array}$ & $\begin{array}{l}\text { Total } \\
\text { cost }(\boldsymbol{\epsilon})\end{array}$ & $\begin{array}{l}\text { Mean cost } \\
(\mathrm{SD}) \text { per } \\
\text { patient }(€)\end{array}$ & Trips & $\begin{array}{l}\text { Total } \\
\text { distance per } \\
\text { patient }(\mathbf{k m})\end{array}$ & $\begin{array}{l}\text { Total } \\
\text { cost }(€)\end{array}$ & $\begin{array}{l}\text { Mean cost } \\
(\text { SD) per } \\
\text { patient }(€)\end{array}$ & $P^{*}$ value \\
\hline \multicolumn{10}{|l|}{ Outpatient service } \\
\hline Dermatology & 2,586 & 393.08 & $22,797.30$ & $162.45(280.92)$ & 906 & 752.3 & $2,629.98$ & $54.79(48.05)$ & n.s. \\
\hline Rheumatology & 78 & 9.85 & 636.67 & $4.75(17.23)$ & 61 & 63.0 & $1,239.11$ & $25.81(81.67)$ & n.s. \\
\hline Digestive system & 56 & 8.04 & 502.39 & $3.75(22.82)$ & 41 & 55.9 & $1,057.82$ & $22.03(76.44)$ & n.s. \\
\hline Internal medicine & 14 & 3.01 & 173.33 & $1.29(10.16)$ & 30 & 53.1 & $1,006.82$ & $20.97(85.88)$ & 0.025 \\
\hline Infectious disease & 14 & 1.85 & 107.47 & $0.80(8.46)$ & 0 & - & - & - & n.a. \\
\hline Subtotal & 2,748 & 415.8 & $24,217.15$ & $173.04(292.86)$ & 1,038 & 924.3 & $5,933.73$ & $123.61(215.37)$ & $<0.001$ \\
\hline \multicolumn{10}{|l|}{ Day hospital } \\
\hline Dermatology & 16 & 11.14 & 626.94 & $4.65(2.13)$ & 17 & 77.1 & $1,691.28$ & $35.22(1.92)$ & 0.003 \\
\hline Rheumatology & 6 & 4.18 & 235.10 & $1.74(0.94)$ & 0 & - & - & - & n.a. \\
\hline Infectious diseases & 0 & - & - & - & 0 & - & - & - & n.a. \\
\hline Subtotal & 22 & 15.3 & 862.05 & $6.39(2.98)$ & 17 & 77.1 & $1,691.28$ & $35.22(62.7)$ & n.s. \\
\hline Total transportation cost & 2,77 & 431.16 & $25,079.20$ & $179.43(292.67)$ & 618 & $1,001.43$ & $7,624.99$ & $158.83(563.95)$ & n.s. \\
\hline
\end{tabular}

SD Standard deviation, n.a. not applicable, n.s. not significant

* Kruskall-Wallis test for the quantitative variable 'mean cost per patient' comparing both drugs

biological agent in our patient cohortprobably as a result of its more recent commercialization-was too low to enable its cost analysis during the first year of treatment.

In any case, we believe our analysis is representative of daily clinical practice since it compares two drugs, which jointly accounted for $70.4 \%$ of our hospital's expenditure on biologicals for the treatment of psoriasis during the studied period. Based on our results, there are no significant differences in efficiency or total cost per patient when etanercept is compared with adalimumab for moderate-to-severe psoriasis not associated with arthritis. Although the overall analysis showed no differences in direct and indirect costs between both drugs, in the specific subanalyses, an increase in direct and indirect costs associated with internal medicine outpatient and day hospital visits, and simple $\mathrm{X}$-rays was found in the adalimumab group as compared to the etanercept group. As there were no differences in the baseline characteristics of patients in each treatment group, a possible explanation is that a selection bias could have been introduced by dermatologists in choosing adalimumab for individuals with non-specific rheumatic symptoms. These symptoms are likely to have motivated the patient to consult the internal medicine specialist. Nevertheless, we know of no data in the clinical history reviewed to support this hypothesis.

In the virtual absence of similar studies, ours can be used as an additional source of information towards placing both etanercept and adalimumab as primary choices for the treatment of plaque-type psoriasis within the scope of the Spanish National Health System. Some design-related factors can alter one's perception of the usefulness of previous studies on this topic. Unlike previous studies, ours provides an approach to a difficult problem that is akin to clinical practice based on real-life 
Table 5 Analysis of direct, indirect, total and per-patient costs associated with the first year of treatment with etanercept and adalimumab

\begin{tabular}{|c|c|c|c|c|c|}
\hline \multirow[t]{2}{*}{ Cost } & \multicolumn{2}{|c|}{ Etanercept $(n=135)$} & \multicolumn{3}{|c|}{ Adalimumab $(n=48)$} \\
\hline & $\begin{array}{l}\text { Total cost } \\
(€)\end{array}$ & $\begin{array}{l}\text { Mean }(\mathrm{SD}) \text { cost } \\
\text { per patient }(€)\end{array}$ & Total cost $(€)$ & $\begin{array}{l}\text { Mean }(\mathrm{SD}) \text { cost } \\
\text { per patient }(€)\end{array}$ & $\overline{P^{*} \text { value }}$ \\
\hline Drug & $1,893,180.75$ & $14,451.76(5,606.17)$ & $696,404.16$ & $14,508.42(9,072.35)$ & n.s. \\
\hline Health-care resource use & $33,825.21$ & $250.55(147.62)$ & $37,144.40$ & $802.45(2,594.67)$ & n.s. \\
\hline Patient transportation & $25,079.20$ & $173.44(292.67)$ & $7,624.99$ & $158.83(563.95)$ & n.s. \\
\hline Productivity loss & $51,819.78$ & $380.98(156.76)$ & $20,970.72$ & $436.90(234.85)$ & n.s. \\
\hline Total first-year costs & $2,003,904.94$ & $14,843.73(6,178.98)$ & $762,144.27$ & $15,405.91(9,106.50)$ & n.s. \\
\hline
\end{tabular}

n.s. Not significant, $S D$ standard deviation

Reported within parentheses are standard deviation values

${ }^{*}$ Kruskall-Wallis test for the quantitative variable 'mean cost per patient' comparing both drugs

use data from a tertiary referral public hospital. First, we chose a period of time for the study to be the first year of treatment with the target drugs. This is very important since, although other studies have tried to predict its long-term course, psoriasis is a chronic disease and differs between patients in natural history and response to treatment, which hinders accurate long-term cost estimations [8, 9]. In the only pharmacoeconomic study of psoriasis reported to date in Spain, Blasco et al. [4] compared the incremental cost-effectiveness per patient of infliximab, etanercept, adalimumab and efalizumab in terms of clinical trial data. They found adalimumab to be the most cost-effective choice, followed by etanercept, efalizumab and infliximab. As noted earlier, however, the corresponding sensitivity analysis revealed a strong overlap between the cost-effectiveness ratios for these drugs. Also, the authors failed to consider the costs involved in hospital resources, transportation and work productivity losses. This precludes accurate interpretation of their results if one considers the significance of all treatment-associated costs in this context. The only study seemingly considering the costs associated with healthcare resource use and work productivity losses was conducted by Sizto et al. [5]. But, in contrast to our study, short-term efficacy was based on relative probabilities of achieving PASI response $(50 / 75 / 90)$ in a meta-analysis of trials, not from clinical data source. This authors found that adalimumab was most costeffective than etanercept, but with confidence intervals overlapping in the sensitive analysis.

There are also some limitations to comparing our results with those of others based on clinical practice owing to differences in study design, variables and objectives. Fonia et al. analysed drug and health-care resource-related costs in a historical cohort of patients with psoriasis seen at a third-level hospital in Great Britain [24] and found the expected increase in costs derived from the introduction of biological agents to be accompanied by a decrease in use of hospital resources by the patients. However, these authors failed to examine costs in terms of the particular drug, which precludes comparison with our results. Subject to similar constraints is the study by Wu et al. [25], who used a USAbased health database to compare the costs of 
various treatment modes with etanercept over a period of 12 months, but considered drugrelated costs alone. Finally, Fowler et al. [26] compared the direct and indirect incremental costs of health care for 12,280 patients with psoriasis and 36,840 controls in terms of information in a database of 30 insurance companies in the USA. Their study included total treatment cost per patient, but excluded disease severity and the effects of each drug separately, which again precludes comparison with our results.

\section{CONCLUSION}

In summary, our data suggest that etanercept is as cost-effective as adalimumab during the first year of treatment in patients with moderate-tosevere psoriasis not associated with arthritis.

\section{ACKNOWLEDGMENTS}

No funding or sponsorship was received for this study or publication of this article. Dr. Ruano is the guarantor for this article and takes responsibility for the integrity of the work as a whole.

Conflict of interest. Dr. Ruano has received honoraria for lecturing and grants for research from Pfizer, honoraria for lecturing from Janssen-Cilag and other financial benefit from Abbott. Dr. Jiménez-Puya has received honoraria for research, advisory board or lecturing from Abbott and Janssen-Cilag, and honoraria for research or lecturing from Pfizer. Dr. RodríguezMartín has received honoraria for consultancy from Pfizer. Dr. Gómez has received honoraria for research from Pfizer and for lecturing from Abbott and Janssen-Cilag. Dr. Vélez has received honoraria for lecturing from Abbott,
Pfizer and Janssen-Cilag, for research from Pfizer and Abbott and for consultancy from Abbott and Janssen-Cilag. Dr. Moreno-Giménez has received honoraria and grants for research, consultancy and lecturing from Merck Sharp \& Dohme, Pfizer, Abbott and Janssen-Cilag. Dr. Isla-Tejera, Dr. Cárdenas and Dr. del Prado-Llergo declare that they have no conflict of interest.

Compliance with ethics guidelines. All procedures were performed in accordance with the ethical standards of the responsible committee on human experimentation and with the Declaration of Helsinki of 1975. Informed consent was obtained from all the patients included in the study.

Open Access. This article is distributed under the terms of the Creative Commons Attribution Noncommercial License which permits any noncommercial use, distribution, and reproduction in any medium, provided the original author(s) and the source are credited.

\section{REFERENCES}

1. Pathirana D, Ormerod AD, Saiag P, et al. European S3-guidelines on the systemic treatment of psoriasis vulgaris. J Eur Acad Dermatol Venereol. 2009;23(Suppl 2):1-70.

2. Menter A, Gottlieb A, Feldman SR, et al. Guidelines of care for the management of psoriasis and psoriatic arthritis: Section 1. Overview of psoriasis and guidelines of care for the treatment of psoriasis with biologics. J Am Acad Dermatol. 2008;58:826-50.

3. Puig L, Carrascosa JM, Daudén E, et al. Spanish evidence-based guidelines on the treatment of moderate-to-severe psoriasis with biologic agents. Actas Dermosifiliogr. 2009;100:386-413 (Article in Spanish).

4. Blasco AJ, Lázaro P, Ferrándiz C, García-Díez A, Liso J. Efficiency of biologic agents in the treatment of moderate to severe psoriasis. Actas Dermosifiliogr. 2009;100:792-803 (Article in Spanish). 
5. Sizto S, Bansback N, Feldman SR, Willian MK, Anis $\mathrm{AH}$. Economic evaluation of systemic therapies for moderate to severe psoriasis. $\mathrm{Br} \mathrm{J}$ Dermatol. 2009;160:1264-72.

6. de Portu S, Del Giglio M, Altomare G, et al. Costeffectiveness analysis of TNF-alpha blockers for the treatment of chronic plaque psoriasis in the perspective of the Italian health-care system. Dermatol Ther. 2010;23(Suppl. 1):S7-13.

7. Schmitt-Rau K, Rosenbach T, Radtke MA, Augustin M. Cost-effectiveness of biological therapy in remission induction of moderate to severe plaque psoriasis. Dermatology (Basel). 2010;221:236-42.

8. Greiner RA, Braathen LR. Cost-effectiveness of biologics for moderate-to-severe psoriasis from the perspective of the Swiss healthcare system. Eur J Dermatol. 2009;19:494-9.

9. Knight C, Mauskopf J, Ekelund M, et al. Costeffectiveness of treatment with etanercept for psoriasis in Sweden. Eur J Health Econ. 2012;13:145-56.

10. Nelson AA, Pearce DJ, Fleischer AB Jr, Balkrishnan R, Feldman SR. Cost-effectiveness of biologic treatments for psoriasis based on subjective and objective efficacy measures assessed over a 12-week treatment period. J Am Acad Dermatol. 2008;58:125-35.

11. Gelfand JM, Kimball AB, Mostow EN, et al. Patientreported outcomes and health-care resource utilization in patients with psoriasis treated with etanercept: continuous versus interrupted treatment. Value Health. 2008;11:400-7.

12. Menter A, Korman NJ, Elmets CA, et al. Guidelines of care for the management of psoriasis and psoriatic arthritis: Section 6. Guidelines of care for the treatment of psoriasis and psoriatic arthritis: case-based presentations and evidence-based conclusions. J Am Acad Dermatol. 2011;65:137-74.

13. Steele T, Pawaskar M, Balkrishnan R, Fleischer A, Feldman SR. Does cost-effectiveness play a role in clinical trials? Dermatol Ther. 2007;20:110-9.

14. Portalfarma.com. Portal de farmacia. Información para farmacéuticos. http://www.portalfarma.com/. Accessed Aug 212012 (Website in Spanish).

15. Boletín Oficial de la Junta de Andalucía (BOJA) No. 210, Oct 27, 2005. Sumario. http://www.junta deandalucia.es/boja/boletines/2005/210/. Accessed 21 Aug 2012 (Website in Spanish).

16. European Commission. Eurostat, European statistics. Available at: http://epp.eurostat.ec. europa.eu/portal/page/portal/eurostat/home/. Last accessed 21 Aug 2012.

17. Autobuses de Córdoba S.A.M. AUCORSA. Available at: http://www.aucorsa.es/. Last accessed 21 Aug 2012 (Website in Spanish).

18. Autopista ES. Coches motor diesel gasolina. Calculadora de coste por kilómetro. http://motor. terra.es/precios-coches/diesel-gasolina/coches-dieselgasolina.htm. Last accessed 3 June 2012 (Website in Spanish).

19. Radio Taxi Córdoba. Available at: http://www. radiotaxicordoba.com/. Last accessed 3 June 2012 (Website in Spanish).

20. Kircik LH, Del Rosso JQ. Anti-TNF agents for the treatment of psoriasis. J Drugs Dermatol. 2009;8:546-59.

21. Turner D, Picot J, Cooper K, Loveman E. Adalimumab for the treatment of psoriasis. Health Technol Assess. 2009;13(Suppl. 2):49-54.

22. R Development Core Team. R: a language and environment for statistical computing, 2008. R Foundation for Statistical Computing, Vienna, Austria. http://www.r-project.org/. Last accessed 17 Nov 2012.

23. Samarasekera E, Sawyer L, Parnham J, Smith CH. Guideline Development Group. Assessment and management of psoriasis: summary of NICE guidance. BMJ. 2012;345:e6712.

24. Fonia A, Jackson $\mathrm{K}$, Lereun $\mathrm{C}$, et al. A retrospective cohort study of the impact of biologic therapy initiation on medical resource use and costs in patients with moderate to severe psoriasis. $\mathrm{Br} \mathrm{J}$ Dermatol. 2010;163:807-16.

25. Wu EQ, Feldman SR, Chen L, et al. Utilization pattern of etanercept and its cost implications in moderate to severe psoriasis in a managed care population. Curr Med Res Opin. 2008;24:3493-501.

26. Fowler JF, Duh MS, Rovba L, et al. The impact of psoriasis on health care costs and patient work loss. J Am Acad Dermatol. 2008;59:772-80. 